\title{
Gender Differences in the Choice of Major: The Importance of Female Role Models
}

\author{
By Catherine Porter and Danila Serra*
}

We conducted a field experiment aimed at increasing the percentage of women majoring in economics. We exposed students enrolled in introductory classes to successful and charismatic women who majored in economics at the same university. The intervention significantly impacted female students' enrollment in further economics classes, increasing their likelihood to major in economics by 8 percentage points. This is a large effect, given that only 9 percent of women were majoring in economics at baseline. Since the impacted women were previously planning to major in lower-earning fields, our low-cost intervention may have a positive effect on their future incomes. JEL: A22, C93, I23, I24, J16

This paper addresses an important constraint that may contribute to the lack of women in traditionally male dominated fields: the scarce number of female role models. Due to historical gender imbalances, it is difficult for young women to come into direct contact with successful women who have majored in male dominated fields and can inspire them to do the same. Lack of representation in introductory textbooks (Stevenson and Zlotnik, 2018) may also contribute to women's inability to see themselves majoring in male dominated fields. We employ a field experiment to examine the impact of an inexpensive and easily scalable role model intervention designed to influence young women's majoring decisions in college.

A number of studies (Jensen and Oster, 2009; Chong and Ferrara, 2009; La Ferrara, Chong and Duryea, 2012) have looked at role model effects in other contexts

\footnotetext{
* Porter: Lancaster University Management School, Lancaster LA14YX, UK. Email: catherine.porter@lancaster.ac.uk. Serra: Corresponding author. Texas A\&M University, Department of Economics, 3094 Allen Building, College Station TX 77843. Email: dserra@tamu.edu. The project was funded by the Undergraduate Women in Economics Challenge (https://scholar.harvard.edu/goldin/UWE) and is registered in the AEA RCT Registry with the unique identifying number AEARCTR-0002879. We thank Claudia Goldin and Tanya Avilova for inspiring us to find ways to reduce the gender gap in the economics major. We are grateful to Kathy Hayes and Santanu Roy for facilitating the implementation of this project, and to all the Principles of Economics instructors for allowing us into their classrooms. We thank the editor and four anonymous reviewers, as well as Rachel Croson, Klaus Desmet, Jason Lindo, Isaac Mbiti, Jonathan Meer, Daniel Millimet, Saltuk Ozerturk, Elira Kuka, David Roodman, Tim Salmon, Laura Schechter and Matt Wiswall and seminar participants at the AEA Meetings, the ESA, the SEA, Southern Methodist University, Texas A\&M University, UCLA Anderson School of Management, and the University of Winsconsin Madison. We are grateful to undergraduate economics students Tracy Nelson and Emily Towler, who played a crucial role in the implementation and success of the study. Finally, we are indebted to the two remarkable women who acted as role models: July Lutz and Courtney Thompson. Without their participation and enthusiasm, this project could have not taken place.
} 
by examining the impact of TV exposure on relevant behaviors, ${ }^{1}$ or by showing inspirational videos (Bernard et al., 2014) or movies (Riley, 2017) to randomly selected individuals. Riley (2017), in particular, provides evidence that in Uganda, exposing students to a (female) role model movie significantly increased performance in qualifying exams, with the impact being larger for female students. ${ }^{2}$

Contrary to previous role model studies, our intervention relies on direct face to face, albeit brief, communication between role models and our target population. Our outcome of interest is female students' decision to major in a male-dominated field. Our setting is a US university. We focus on economics, a field that, contrary to other subject matters - including physical sciences, mathematics and business studies $^{3}$ - has made little progress over the years in attracting women. In the US, the percentage of bachelor degrees awarded to women has risen from about 25 percent in the 1950s to over 50 percent in the 2000s (National Center for Education Statistics and NSF, Science \& Engineering Indicators, 2016), yet only 30 percent of bachelor degrees in economics are awarded to women, the same percentage as in the mid 1990s.

In the specific context of majoring choices, several studies estimate the impact of female teachers on female students attitudes and behaviors and attribute this to a role model effect. ${ }^{4}$ The evidence is especially strong for STEM majors (Lim and Meer, 2019; Carrell, Page and West, 2010). ${ }^{5}$ However, since instructors may give more attention or otherwise behave differently toward students of the same gender, the mechanism of causality cannot be clearly delineated. In contrast, our study isolates the role model mechanism by focusing on women who are not teachers, have no prior or subsequent relationship with the target students, and give just one short speech to audiences made of male and female students.

Following Morgenroth, Ryan and Peters (2015), we define female role models as women who can 'influence role aspirants' achievements, motivation, and goals

\footnotetext{
${ }^{1}$ For instance, La Ferrara, Chong and Duryea (2012) show that in Brazil, exposure to soap operas where the majority of the main female characters had either no children or only one child significantly decreased women's fertility.

${ }^{2}$ In India, Beaman et al. (2012) have shown that an increase in the presence of women in government councils in India significantly affected the aspirations of young women and eliminated the gender gap in educational attainment among adolescents.

${ }^{3}$ About 47 percent of business degrees, 46 percent of natural sciences degrees and 43 percent of math degrees and 39 percent of physical science degrees are currently awarded by women.

See: https://nces.ed.gov/programs/digest/current_tables.asp, last accessed 31 May 2019.

${ }^{4}$ For a review, see Allgood, Walstad and Siegfried (2015) and Bayer and Rouse (2016).

${ }^{5} \mathrm{Lim}$ and Meer (2019) exploit the random assignment of students to classrooms in Korean middle schools and find that female students that are matched with female math teachers in 7 th grade are more likely to take advanced math courses in high school, to attend a STEM-focused high school and to plan to major in STEM. Carrell, Page and West (2010) find that the proportion of mandatory introductory courses taught by female professors at the US Air Force Academy significantly increases the likelihood that top female students, as measured by their SAT math score, would complete a STEM major. A few studies in social psychology have investigated the impact that role models may have on female students' attitudes toward male-dominated fields. For instance, Stout et al. (2011) conducted experiments where math or STEM majors are either exposed to confederates posing as math majors (study 1) or are asked to read biographies of female versus male engineers (study 2). The outcome variables are students' subsequent answers to Implicit Association Tests aimed at measuring implicit attitudes toward math or STEM, as well as direct elicitation of such attitudes.
} 
by acting as behavioral models, representations of the possible, and/or inspirations" [p.4]. Our role models are two successful and inspiring career women who had majored at the same university as the target population. Our experiment consisted in the random selection of Principles of Economics classes - which are typically gender balanced in our setting - to be visited by the role models. Each visit consisted of a 15-minute discussion about the role model's experiences as an economics major, a description of their career paths and achievements, and an explanation of how their specific major (economics) contributed to their success on the job. Since treatment and control classes existed and were taught by the same instructors also the year preceding the intervention (Spring 2015), we are able to employ a difference-in-differences estimation strategy to assess the impact of the role model visits on students' interest in the economics major. Hence, our methodology allows us to clearly identify the impact of the role models on female students' education choices. ${ }^{6}$

We have four outcome variables: enrollment in an Intermediate Economics class the year after taking the Principles class, enrollment in one or more economics classes at any time after Principles, the total number of economics classes taken after Principles, and, ultimately, the decision to major in economics.

An important feature of our design is the method we used to select the role models according to pre-determined criteria aimed at finding career women that would be particularly appealing to female students. We enlisted the help of two female students currently majoring in economics. The students shortlisted economics alumni on the basis of their interests in their current sectors of work. We then contacted the selected alumni and invited them to be interviewed via Skype. The students conducted scripted interviews with the finalists who agreed to be interviewed, and chose the best two on the basis of their assessment of the alumni's jobs, communication skills and overall charisma. While there were men in our set of interviewed finalists, both finally chosen role models were women. ${ }^{7}$ This is in line with social psychology studies (Lockwood, 2006; Stout et al., 2011) showing that women are more likely to identify with and be inspired by female than male role models.

Our results show that the role model intervention had a significant impact on all outcomes for female students. Specifically, being in a class that received the role model visits increased the likelihood that a female student would major in economics by 8 percentage points, over a baseline of 9 percent, i.e., we estimate nearly a 100 percent increase in the share of female economics majors. Similar effects are observed on intermediate outcomes. The likelihood that a female student

\footnotetext{
${ }^{6}$ An unpublished study that is methodologically related to ours, despite obvious differences in context, target population and outcomes of interest, is Nguyen (2008), which is based on a field experiment in Madagascar where 4th grade students and their parents were presented with either statistics about returns to education or with speeches from role models about their experiences, or both, employing a total of 72 different role models chosen by the school district head, a local NGO leader, and community leaders.

${ }^{7}$ The men in the sample were not deemed as the most inspiring by our two female students. For further discussion, see Section I.B.
} 
would take an intermediate economics class the year following the Principles class also doubled, increasing by 11 percentage points over a baseline of 11 percent; similarly the likelihood of taking another economics class at any time after the Principles class increased by 14 percentage points over a baseline of 18 percent. While men were not the focus of the intervention and we did not have any priors on whether and how they would be impacted, we do have data on male outcomes and we perform a triple-difference regression as a robustness check. The results show that men were unaffected by the treatment.

By examining which majors saw a significant decline in female students, we are able to assess which fields of study the impacted female students would have majored in, absent the intervention. This is important, since, if we were pulling women away from other male-dominated fields also leading to high-paying jobs e.g., STEM - our intervention would possibly be counter-productive, as it would diminish gender diversity in other male-dominated fields and possibly lower the earnings potential of our target population. Our data suggests that the role model intervention did not decrease the percentages of women majoring in maledominated fields leading to high wages, i.e., STEM, business and finance. Instead, the intervention significantly lowered the percentage of women planning to major in humanities. The analysis of the grades obtained in a standardized exam given to all Intermediate Economics students shows that the treated female students performed as well as the control students, suggesting that the students swayed to study economics by our intervention were not less skilled or less likely to succeed in the program. We conclude that the economic impact of our low-cost role model intervention may be significant, as the future wages of our target population could be substantially larger as a result.

Our study contributes to the role model literature as well as the literature on the causes of the under-representation of women in certain fields of study. This includes investigations of the importance of gender differences in math aptitude (Emerson, McGoldrick and Mumford, 2012), sensitivity to grades (Rask and Tiefenthaler, 2008; Goldin, 2013; Kugler, Tinsley and Ukhaneva, 2017), competitiveness (Reuben, Wiswall and Zafar, 2017; Buser, Niederle and Oosterbeek, 2014; Flory, Leibbrandt and List, 2014) ${ }^{8}$ taste for the subject matter (Dynan and Rouse, 1997; Wiswall and Zafar, 2014) $)^{9}$ and preferences over different job attributes, which are linked to different majors (Wiswall and Zafar, 2017). ${ }^{10}$ Our work also relates to recent investigations of the effects of mentorship programs on individual behaviors (Blau et al., 2010; Dennehy and Dasgupta, 2017; Kofoed et al., 2019). ${ }^{11}$

\footnotetext{
${ }^{8}$ For seminal evidence on gender differences in competitiveness, see Niederle and Vesterlund (2007). (2016).

${ }^{9}$ For a review of the literature, see Allgood, Walstad and Siegfried (2015) and Bayer and Rouse ${ }^{10} \mathrm{Th}$ provide flexibility and job stability.

${ }^{11}$ See Athey, Avery and Zemsky (2000) for a theoretical investigation of the importance of mentoring within organizations.
} 
Overall, our study provides strong evidence of the impact of female role models on women's self-selection into fields of study in which men are traditionally overrepresented. Our analysis of mechanisms suggests that, although the role models shared novel information on the jobs associated with an economics degree, the increase in information is not responsible for the observed impacts, which leads us to conclude that the mechanism might be inspiration.

Achieving higher gender diversity within majors is important and desirable as it may enhance productivity and overall performance in team work, and it may contribute to the production of novel ideas (Bayer and Rouse, 2016; Ellison and Mullin, 2014; Hoogendoorn, Oosterbeek and Van Praag, 2013; Bear and Woolley, 2011). Moreover, the choice of major significantly affects one's earnings potential (Arcidiacono, 2004; Kirkeboen, Leuven and Mogstad, 2016), and male-dominated fields tend to lead to higher paying jobs. Economics, for instance, is the highest earning major in the social sciences (Black, Sanders and Taylor, 2003; Carnevale and Cheah, 2015) and has been shown to generate higher earnings than a business degree (Black, Sanders and Taylor, 2003). ${ }^{12}$ Greater gender diversity may also have important consequences on aggregate outcomes. Indeed, under the assumption of no gender differences in innate abilities, gender imbalances in self-selection into fields of study (and subsequent careers) may result in misallocation of talents - where individuals are not pursuing their comparative advantages - that could significantly affect aggregate outputs, as recently shown in Hsieh et al. (2013). Increasing the number of women studying economics may be especially relevant for real-world aggregate outcomes, as there is evidence (May, McGarvey and Whaples, 2014; May, McGarvey and Kucera, 2018) that female and male economists both in the US and in Europe have significantly different views on a variety of policy issues, including government intervention, market solutions, environmental protection and gender equality.

What makes our study unique is the use of a controlled field experiment, which allows clear identification of the impact of the role models, and the novel methodology employed to identify such role models, which crucially relied on the opinions of current female students. The simplicity of the experimental design makes our intervention easily replicable (in economics as well as in other male-dominated fields) and scalable, and suggests that the long-term goal of moving towards gender parity in the economics profession at all levels could be achieved at a relatively low cost by exposing students enrolled in principles classes to successful and inspiring alumnae.

The paper is organized as follows. In Section I we describe the field experiment, the university setting in which it was implemented and our empirical strategy. Section II describes our results and Section III reports robustness checks. Then, in Section IV, we discuss the possible mechanisms behind the success of the

\footnotetext{
${ }^{12}$ Using recent census data, Carnevale and Cheah (2015) also report that the median salary of an experienced worker, aged 30 to 54 years of age, who majored in economics is the highest in the social sciences and the thirteen highest among all majors.
} 
intervention and in Section $\mathrm{V}$ we conclude with some final remarks.

\section{Experimental Design}

As part of the study, we: 1) conducted a survey of students enrolled in Principles of Economics classes in Spring 2015 and Spring 2016; 2) implemented a field experiment consisting in randomly selecting 4 of the 10 Principles of Economics classes offered in Spring 2016 to receive visits by two carefully chosen role models; and 3) obtained administrative data on the study paths of the students in our 2015 and 2016 samples. In this section, we start by describing the university setting where the experiment took place (Section I.A). We then provide details about our field experiment and study procedures (Section I.B). We conclude by describing our estimation strategy (Section I.C).

\section{A. The University Setting}

We conducted our study at Southern Methodist University (SMU). Although $\mathrm{SMU}$ is a small private university, ${ }^{13}$ the number of students majoring in economics every year, averaging 166 between 2009 and 2015, is comparable to that of larger universities and is in line with the average number of economics majors across the top 100 US universities (Goldin, 2015). ${ }^{14}$

SMU operates over two semesters: a Fall semester, starting in August and ending in December, and a Spring semester, starting in January and ending in May. Our study involves students enrolled in Principles of Economics classes in either Spring 2015 or Spring 2016. ${ }^{15}$ Principles of Economics classes are especially popular at SMU, with over 600 students enrolled and multiple classes or sections - being offered every semester. Crucially, these classes are typically gender balanced, with women making up between 44 and 47 percent of the enrolled students in the past 6 academic years. ${ }^{16}$ In contrast, the next class up Intermediate Microeconomics - for which the Principles class is a prerequisite is gender imbalanced, with only about 26 percent of the enrolled students being women (2009-2015 average). The gender imbalance remains and even worsens by the time of graduation, with less than one fourth of economics degrees being

\footnotetext{
${ }^{13} \mathrm{SMU}$ is located in Dallas, Texas. In the latest (2019) university ranking provided by the US News and World Report, SMU appears ranked 59th in the nation, same as the University of Washington and Pennsylvania State University. In 2015, SMU had a total of 11,739 students. For additional information about SMU, see: http://www.smu.edu/AboutSMU/Facts

${ }^{14}$ See: https://scholar.harvard.edu/files/goldin/files/planninggroup_data_notes_0.pdf

${ }^{15} \mathrm{SMU}$ also has two 4-week long Summer terms, in June and July. Classes held during the summer are very different than standard classes, as they take place daily and they are typically very small (i.e., less than 20 students). The student population taking summer classes is also quite different, i.e., typically older and in need of credit hours, e.g., in order to graduate by an imminent date. Given these differences between summer classes and regular classes, we exclude summer classes from our analysis.

${ }^{16}$ One reason for the high number of students taking the Principles classes is the presence of a Business School, which requires prospective students to take such classes.
} 
awarded to women, the average being 21 percent between 2009 and 2015. This is below the national average of 30 percent (Bayer and Rouse, 2016). Using Goldin (2015)'s conversion ratio, which is the ratio of the percentage of men majoring in economics to the percentage of women majoring in economics in a given university, SMU has a score of 4.493 (2011-2013 average), meaning that there are more than 4 men for every woman majoring in economics. This is substantially higher than the average for the top 100 US universities computed for the same time period, which is equal to 3 .

The above statistics make SMU the ideal setting for a study aimed at increasing the percentage of women majoring in economics. Below, we provide details on our experimental design and empirical strategy.

\section{B. The Field Experiment}

The study started in Spring 2015, when we surveyed all students taking Principles of Economics classes. There were 11 classes being offered and taught by seven instructors, four women and three men, at different days and times of the week. ${ }^{17}$ Students could enroll in any of the available classes following a first come first serve rule. A total of 722 students took a Principles class in Spring 2015. We conducted our survey in the last week of classes at the end of April 2015, involving about 75 percent of the sample. ${ }^{18}$ We collected demographic characteristics and we asked questions on intended major. We also elicited beliefs about the kinds of jobs associated with the economics major. We conducted an identical survey the following year, at the end of April, with the 2016 Spring Principles cohort.

In Spring 2016, the same classes - meaning classes taught on exactly a given day and time of the week, by a given instructor - were offered as in Spring 2015, with two exceptions. ${ }^{19}$ A total of 688 students were enrolled in a Principles class that semester; we have survey data for about 70 percent of them. ${ }^{20}$ In Spring 2016, there were 4 small classes (i.e., capped at 40 students) and 6 large classes (i.e., of 100 or more students) being offered. The enrollment class caps are decided by the department of economics on the basis of classroom and instructor availability. They are not dictated in any way by student demand. At any time during the class enrollment period, students can only enroll in classes whose cap size has not been met yet.

Since we aimed to have a balanced number of students in the 2016 treatment and control classes, we stratified our class-level randomization by class size. We

\footnotetext{
${ }^{17}$ Three instructors taught two classes each.

${ }^{18}$ The survey was conducted during class time. Therefore, we have data only on the students that were present the day of the survey.

${ }^{19}$ Two instructors taught two classes each. One instructor who taught two classes in 2015 only taught one class in 2016, hence the number of classes being 10 rather than 11 in Spring 2016. One control class changed instructor and weekly schedule in 2016. In Section 5, we conduct robustness checks of our main findings by dropping the classes that changed between the two years and including class fixed effects in the empirical specification.

${ }^{20}$ Again, participation in the survey was conditional on class attendance.
} 
randomly selected one small class and three large classes to receive the role model intervention. Note that our randomization also defined treatment and control classes in Spring 2015, even though the treatment classes were treated only in 2016. The fact that treatment and control classes existed the year prior the intervention allows us to employ a difference-in-differences estimation strategy, as discussed in Section I.C.

Our target population was the set of female students enrolled in Principles of Economics classes. Hence, we aimed to select role models who could be especially appealing and inspiring to young women. To this end, we enlisted the help of two undergraduate female students who were majoring in economics at the time (Fall 2015). We first obtained the list of alumni who graduated between 1985 and 2010 and then preceded to shortlist 18 role model candidates based purely on the female students' interest in the their sector of work and current job. We contacted the shortlisted candidates via email asking for their availability and willingness to be interviewed via Skype by our female students. The email did not mention the specific aim of the study; it only stated that the economics department had shortlisted 18 especially inspiring alumni ${ }^{21}$ and we aimed to gather some additional information about their current position, as well as their previous jobs and their experience as an economics student at SMU. ${ }^{22}$

Seven alumni replied expressing their availability for and interest in the Skype interview. The Skype (scripted) interviews were conducted by our two female students, which then proceeded to select our final two role models based on their impressions on the candidates' jobs, their appreciation for the field of economics, and, crucially, their communication skills and overall charisma. Both finally selected role models are women. One role model graduated in 2008 and started her career by working in management consulting for two years. She had then decided to completely change her career path by going to work for an international NGO in Nicaragua, and then as a director of operations at a toy company based in Honduras. She now works in Operations at a fast-growing candy retail company. The second role model graduated in 1991 and has had a stellar career in marketing, becoming the senior director of North American Marketing \& Information Technology at a large international communications company. While the two role models work in very different sectors, what they have in common is that their jobs are not stereotypically associated with the economics major.

We formally invited each role model to visit SMU in Spring 2016. Both role models accepted our invitation and independently visited four Principles of Economics classes - our treatment classes - between March and April 2016. The first role model visited each class on March 21st or 22nd, depending on the class schedule. The second role model visited each class on April 6th or April 7th. The 2016 survey took place on the last week of classes, at the end of April 2016. All treatment classes received a visit from both role models, therefore we cannot

\footnotetext{
${ }^{21}$ We did not restrict the selection to females. Therefore, we initially shortlisted 8 women and 10 men.

${ }^{22}$ The specific content of the email is available upon request.
} 
differentiate the impact that each role model, i.e. their specific individual characteristics, may have had on the treated students. We can only identify the joint impact of the two alumnae on the students' interest in the economics major.

The purpose of the role model visits was for the two alumnae to talk about their experiences as economics majors, their career choices and their current jobs. More importantly, we asked them to discuss how majoring in economics helped them succeed in their careers. We also emphasized that it was important to try and involve students in the discussion (e.g. welcoming their questions) as much as possible.

We did not inform the class instructors about the purpose of study, to avoid possible changes in instructors' behavior as a result of the intervention. We also did not inform the role models about the objective of the research study and therefore they did not know that we intended to examine the impact that their visit would have on female students' decision to continue studying economics. As a result, the speeches to the classes were gender-neutral, i.e., no gender-specific issues were discussed. This allows us to examine whether and to what extent our career women were perceived as role models also by male students. While we did not have a clear prior on the impact that the role models would have on men, the fact that the career women were chosen by female students to be inspiring to fellow young women suggests that the impact on men would most likely be lower. In the results section, we focus exclusively on the impact of the intervention on our target population - female students. However, we also conduct robustness checks where we treat the men as an additional control group.

It is important to note that the selected role models happened to both be female, as these two were the most inspiring to the undergraduate female students that assisted us in the role model selection process. ${ }^{23}$ Ideally, we would have liked to also include a treatment that exposed students to two "identical" male role models in order to disentangle the role of gender matching from the role of information about the two specific career paths chosen by our female role models. However, even if we had a sample size large enough to include an additional set of treatment classes in our study (which we did not), it would have been impossible to find male "clones" of our female role models, i.e., two men with same career profiles, comparable levels of charisma and other individual characteristics to create the perfect male counterfactual treatment. ${ }^{24}$ We can however use insights from studies in social psychology (Lockwood, 2006; Stout et al., 2011), which show that women are more likely to identify with and be inspired by fellow women. This suggests that, everything else being equal, the impact of the intervention would

\footnotetext{
${ }^{23}$ The initial shortlist did include males, and three men made it to the Skype interviews but were ultimately not chosen by the two female students that conducted the scripted interviews.

${ }^{24}$ While videotaping the role models and using male actors to reproduce their speeches would theoretically be possible, in practice, the use of actors presenting themselves as working in given fields and having very specific study and work experiences would imply deceiving the students in the audience. Even if deception were not a problem, the Q\&A section of the classroom visits would be difficult to predict and handle by actors, as it may involve job specific questions and students' requests of business cards and contact details.
} 
have been lower if the role models had been men.

\section{Empirical Strategy}

As outlined above, the treatment took place at the class level in 2016, yet the treatment and control classes also existed in 2015. Since we had a small number of classes over which we randomized, it was unlikely that we would achieve a balance between treatment and control groups. ${ }^{25}$ We acknowledge that each class may have different types of students since we have self-selection into classes, and that students in different classes are likely to be subject to different stimuli, as they are exposed to different instructors, curricula and teaching styles. Therefore, we take advantage of the fact that the same classes (i.e., same instructors and time schedules) were offered both in 2015 and 2016 to estimate our treatment effects using a difference-in-differences model as the optimum strategy (Angrist and Pischke, 2008). Since class attendance was not mandatory the days of the role model visits, the estimate can be seen as the intent-to-treat effect of the intervention using equation 1 below,

$$
Y_{i}=\beta_{0}+\beta_{1} d t_{i}+\beta_{2} d T_{i}+\beta_{3} d t_{i} * d T_{i}+\delta \mathbf{X}_{i}+u_{i}
$$

where $Y_{i}$ is our proxy for female student $i$ 's interest in the economics major; $d t$ is a dummy equal to 1 if she took the class in 2016 and 0 if she took a class in 2015; $d T$ is a dummy equal to 1 if she is in a treatment class and 0 if he or she is in a control class. The interaction between these two dummies is our coefficient of interest (i.e. post*treat). ${ }^{26}$ As noted above we allow for imbalance in pretreatment characteristics across classes by including $X$, a vector of demographic controls and class characteristics, to account for slight differences seen in our balance tests (see below for further discussion).

As a robustness check, we also include class fixed effects as shown below (omitting the treated class dummy and the class characteristics). However, this reduces the sample size, since only nine classes did not change time of instruction or teacher between the two years..

$$
Y_{i}=\beta_{0}+\beta_{1} d t_{i}+\beta_{3} d t_{i} * d T_{i}+\delta \mathbf{X}_{i}+\lambda C_{j}+u_{i}
$$

As a further robustness check, we include male students as an additional control

\footnotetext{
${ }^{25}$ However, simple pair-wise chi-square tests of the difference between treatment and control outcomes do show significant difference in our outcome variables, as shown in Table I.

${ }^{26} \mathrm{We}$ could also have estimated only the difference post-treatment for only those in treated classes. However, if we found a significance difference in the outcomes of students enrolled in post- and pretreatment treatment classes we could not confidently attribute that difference to the intervention, as both students' characteristics and teaching methods may have changed between the two years.
} 
group and employ a triple difference specification as shown in equation 3 below, with notation as above, but adding a dummy for female student, $d F$ which is interacted with the treatment class, the treatment year and the interaction of the two.

$$
\begin{array}{r}
Y_{i}=\beta_{0}+\beta_{1} d t_{i}+\beta_{3} d t_{i} * d T_{i}+\beta_{4} d F_{i}+\beta_{5} d t_{i} * d F_{i}+\beta_{6} d T_{i} * d F_{i} \\
+\beta_{7} d t_{i} * d T_{i} * d F_{i}+\delta \mathbf{X}_{i}+\lambda C_{j}+u_{i}
\end{array}
$$

Our final outcome variable is a student's decision to major in economics. We also examine the effect of our treatment on intermediate outcome variables that can show the pathway to choosing a major, or the student's interest in the economics major. We first look at whether the student enrolled in Intermediate Microeconomics the following academic year, either in Fall or Spring. We then create a dummy equal to 1 if the student took any further economics courses at any time after the Principles class. We then look at the number of economics courses chosen, and finally examine the decision to declare the economics major. We use regression analysis (Linear Probability Model, or LPM), and given the dichotomous nature of most of our dependent variables, we provide robustness tests for equation 1 using probit estimates.

As our treatment is at the class level, we cluster the standard errors at the class level (Abadie et al., 2017). Since there are fewer than 30 clusters (12 classes), we follow Angrist and Pischke (2008) and Cameron and Miller (2015) and apply the correction for the small number of clusters by using wild cluster bootstrapping (Cameron and Miller, 2015). ${ }^{27}$

Finally, we note that, since students from the 2016 treated classes may have talked about the role model visits with their peers in control classes, the treatment effects may have spilled over into untreated students. This implies that our estimates should be interpreted as a lower bound of the actual impact of the intervention on students' study choices.

\section{Results}

In this section, we start by providing descriptives of our data and conducting balance tests. Then, in Section II.B and Section II.C we report and discuss our main results on the impact of the role model intervention on intermediate and final outcomes. The next subsection, Section II.D, examines where we attracted the female students from, i.e., which fields of study saw a decline in female students as a result of the intervention. Finally, in Section II.E we ask whether the impacted female students were less likely to succeed within the economics major

\footnotetext{
${ }^{27}$ In a previous draft of the paper we clustered at the class-year level (21 clusters) and obtained similar results. In the current draft, we follow Abadie et al. (2017) to cluster at the class level only. Note also that probit model with score wild Bootstrapped standard errors (Kline, Santos et al., 2012) gives extremely similar results and these are presented in the Appendix for convenience.
} 
by looking at the performance of students from treatment versus control classes in the Intermediate Microeconomics class.

\section{A. A first look at the data}

We have information on a total of 1397 students who took a Principles of Economics class in either Spring 2015 (712) or Spring 2016 (685). Of them, 45 percent (627) were women. Of the Spring 2016 cohort, 49 percent (339) of the students were in a class which was treated, i.e. visited by the role models. While the gender compositions of the treatment and control classes in 2015 are not significantly different from each other, with 46 percent and 44 percent of students being women, respectively, in 2016 the treatment classes had significantly fewer women enrolled than the control classes (38 percent versus 51 percent, p-value of $0.001)$.

\section{- Insert Table I here -}

In Table I, we report descriptive statistics and conduct balance tests using both the administrative data and the survey data. In particular, from the administrative data we have information on the students' in-state or out-of-state status, their year of study, e.g. whether they are freshmen, their cumulative GPA, whether they are American or international students. From the survey data we have information about whether they belong to a sorority, whether they are athletes and whether they took an economics class in high school. ${ }^{28}$

Testing for differences in female student characteristics between control and treatment classes in 2016 shows some significant differences, as might be expected given the small number of classes from which we were able to randomize our treatment and control sets of students. In particular, we see that there are significantly fewer American students in the treatment group, as well as more freshmen. Moreover, the cumulative GPA of students enrolled in treatment classes is slightly lower. We do not see any significant differences in the survey-based individual characteristics between treatment and control classes.

We take the imbalances observed in the data into account in our empirical analysis in Section II.B and Section II.C, where we include all the available student characteristics in our set of controls, and show robustness checks with class fixed effects, and using probit estimates. We check the effect of the role model visits on grades in the Principles class and following Carrell, Page and West (2010), we also estimate treatment effects separately for the top performing female students, in an attempt to identify the marginal students who were affected by the intervention the most.

Figure I and Table II show a summary of the significant post-treatment outcome differences in our main outcomes of interest to motivate the further analysis. We

\footnotetext{
${ }^{28}$ We report balance tests for the male sample in Table A1 in Appendix.
} 
report descriptive statistics and p-values for: i) percentage of female students who took an Intermediate Microeconomics class the year immediately following their Principles class, i.e. either Fall 2015 or Spring 2016 for the 2015 cohort, and either Fall 2016 or Spring 2017 for the 2016 cohort; ii) percentage of female students who took another economics class after Principles at all; iii) number of economics classes taken overall and iv) percentage who majored in economics. Note that at SMU, students can declare their major at any time after having completed 30 credit hours (in any field). There is no deadline for declaring a major; thus, students can choose their major at any time, up to their final semester at SMU. We obtained our majoring data in January 2019. At that time, only 31 students in our sample (2.22 percent) had not declared their major. ${ }^{29}$

- Insert Figure I here -

- Insert Table II here -

\section{B. Intermediate Outcomes: Enrollment in Intermediate Micro within year and enrollment in any class after Principles}

We examine two intermediate outcomes of the intervention: 1) enrollment in Intermediate Microeconomics within a year from the Principles class, and 2) enrollment in at least another economics class at any time after the Principles class.

Intermediate Microeconomics is a prerequisite for upper level economics classes. If a student wants to major in economics, s/he needs to take this class, the sooner the better. We therefore consider this a good measure of the short-term impact of the intervention. ${ }^{30}$ As shown in Table II, in 2015, the proportion of women who enrolled in Intermediate Microeconomics within a year from Principles is around 13 percent, and is the same across treatment and control groups. In 2016, the proportion in the untreated classes is 10.73 percent, whereas over 18 percent of women in the treated classes had enrolled; this difference is statistically significant $(p=0.05)$. Similarly, the likelihood of taking another economics class at any time after Principles is significantly different for the treatment versus control classes in 2016 , with the percentage of women taking at least one more economics class up to 28 percent in the treated group as compared to 18 percent in the 2016 control group.

\section{- Insert Table II here -}

\footnotetext{
${ }^{29}$ However, the college subdivision of these students indicates that they would major in a humanities field. We classify students with two or more declared majors as "economics majors" as long as one of their majors is economics.

${ }^{30}$ Administrative data on students who took Principles of Economics in the Spring semesters of 2008 or 2009 and completed their degree by Fall 2014 show that about 80 percent of the 2008 and 2009 cohorts who majored in Economics took the Intermediate class the year following their Principles class. This compares to 21 percent of students who were in the same Principles classes and did not major in Economics (differences significant at the 1 percent level).
} 
Next, in Table III we present results from the regression analysis, which allows us to examine the effects of the role model intervention on female students by conducting difference-in-differences estimation, as explained in Section I.C. Columns 1 and 2 show the LPM results when the dependent variable is a dummy equal to 1 if the female student took the Intermediate class in the year directly following their Principles class, and 0 otherwise. ${ }^{31}$ In columns 3 and 4 the dependent variable is a dummy variable equal to 1 if the student took at least another economics classes after Principles, and 0 otherwise. In the first and third columns, we employ our most parsimonious specification, which only includes the 2016 year dummy, the treatment class dummy and the interaction between the two. In the second and fourth columns, we include all the controls obtained from administrative data, for which we provided summary statistics in Table I. We also control for a dummy equal to 1 if the female student was in a small class, and a dummy equal to 1 if the class was taught by a female professor. Finally, we include the grade that she obtained in the Principles class, as we observe significantly lower grades in treatment than control classes in 2016 (2.86 versus 3.11, significant at the 5 percent level) and there is evidence (Goldin, 2013; Rask and Tiefenthaler, 2008) that women's decision to study economics is affected by the grades obtained in introductory courses. Note that in Section III.B we analyze student performance in the Principles class and find that the lower grades observed in the treated classes are not a result of the intervention itself.

For all specifications we report p-values obtained when implementing a wild cluster bootstrap to correct for the small number of clusters (Cameron and Miller, 2015) using the command 'boottest' (Roodman et al., 2019). Note that this method does not assume normality and therefore does not calculate standard errors. For ease of interpretation we also report $95 \%$ confidence intervals in the main results tables. Estimates generated by probits with score bootstrapped p-values (Kline, Santos et al., 2012) are reported in Table A2 in the Appendix.

\section{- Insert Table III here -}

We find strong evidence that the intervention had a positive and significant effect on women's enrollment rates in further economics classes. The interaction term is significant for both intermediate outcomes under investigation. The role model visits increased the likelihood that a female student who took a Principles of Economics class would enrol in Intermediate Micro within a year by 11 percentage points. This is quite a considerable effect, considering that the average baseline enrollment rate (considering both 2015 and 2016) is just below 12 percent. In fact, our estimates suggest that the role model intervention almost doubled the percentage of female students taking Intermediate Micro the academic year following their enrollment in a Principles class.

The results are qualitatively similar for the likelihood of enrolling in another economics class at any time after the Principles class. The intervention increased

${ }^{31}$ We analyze men separately in Appendix. 
such likelihood by about 14 percentage points, which represents a 70 percent increase, given the average baseline enrolment level.

\section{Final Outcomes: Number of Economics Classes taken and Majoring in Economics}

Our final outcomes are the total number of economics classes taken and the decision to major in economics. Table II and Figure I show significant differences emerging post-treatment in both outcomes for the treated women. The average number of economics classes taken by female students after Principles increased from about 0.85 to 1.42 (significant at the 10 percent level). The percentage of women who declared the economics major increased from below 9 percent (averaged across years) to above 15 percent $(p=0.04)$.

As before we present regression results with and without controls. Table IV shows the impact of the intervention on the number of economics classes taken after the Principles class (columns 1 and 2) and the final decision to major in economics (columns 3 and 4), whereby the dependent variable is equal to 1 if the student majors in economics and a zero otherwise.

\section{- Insert Table IV here -}

We find that the treated women took around half an economics class more on average than untreated women over the course of their studies, though the effect is marginally insignificant $(\mathrm{p}=0.115)$ when a full set of controls are added (column 2). The effect of the role model visits on the final majoring decision remains significant, up to around 2 years after the treatment. Specifically, we see an 8 percentage point increase in treated women declaring Economics as their major. Again, due to a fairly low baseline of just under 9 percent the effect is quite large, as it converts to almost a 100 percent increase in the likelihood that women enrolled in introductory classes would end up majoring in economics.

Our estimated marginal effects are comparable in size to those found in other studies that exploit random allocation of students to teachers to examine the impact of female teachers on female students' education choices. In particular, Lim and Meer (2019) show that in Korean schools, female students who are taught by a female versus a male math teacher in 7 th grade, are 15.1 percentage points more likely to choose the math-science track in high school and 15.7 percentage points more likely to take at least one advanced math course. Carrell, Page and West (2010) found that being assigned exclusively female professors in introductory math and science courses at the US Air Force Academy increased the likelihood that (only) the top female students would major in STEM by 26 percentage points, as compared to having exclusively male faculty.

Following Carrell, Page and West (2010), we investigate whether the role model intervention was especially impactful on top female students, which we define as those who have a cumulative GPA $\geqslant 3.7 .^{32}$ About 30 percent of all female

\footnotetext{
${ }^{32}$ We do not have data on university entry exams or high school performance that we could use as an
} 
students belong to the top student category with no significant differences across years and treatment and control classes. In Table A3, we replicate the analyses conducted in Tables III and IV while restricting the sample to the top female students. Keeping in mind that our sample size is severely reduced, the impact of the intervention on the intermediate outcomes is striking: the marginal effect of the role model visits is 26 percentage points on enrollment in Intermediate Microeconomics within a year from Principles. This percentage point increase resembles very closely that found by Carrell, Page and West (2010). However the rest of the outcomes show no significant changes when the analysis is restricted to the top female students, possibly due to the small sample size.

\section{Where are we attracting female students from?}

Overall, our empirical estimates show that the role model intervention had a positive, significant and sizeable impact on female students' interest in the field of economics. While we believe that achieving gender balance in a male dominated field like economics should be seen as a goal in itself, role model interventions like ours would be especially desirable if they could positively affect the earnings potential of female students that would otherwise major in a field conducive to lower incomes than their male counterpart. Conversely, having an intervention that attracted toward economics female students who would have otherwise majored in another male-dominated high-earnings field (e.g. finance or STEM), may be counter-productive in terms of its overall economic impact.

- Insert Figure II here -

Here we use administrative data on the majoring decisions of the students in our sample to identify the fields of study that saw a reduction in female students' interest as a result of our intervention. We distinguish between high-earning majors, defined as STEM, finance, business and marketing, and low-earning majors, defined as other social sciences (e.g., psychology, anthropology and political science), arts, communication studies, and humanities and languages.

- Insert Figure III here -

Figures II and III display the percentage female students, in control and treatment classes in 2015 and 2016, majoring in each field of study, grouped in either the high-earning or the low-earning category. Figure II shows that the role model intervention did not cause a decline in women's interest in any of the high-earning majors. Figure III suggests that the role model intervention reduced the percentage of women majoring in humanities. This is confirmed by regression analysis, as shown in Table $\mathrm{V}$, which displays the results obtained for high-earning majors, and Table VI, which display results obtained for low-earning majors. In each

alternative proxy for student ability. 
column, the dependent variable is a dummy equal to 1 if the student majored in the field under consideration, and 0 otherwise. The estimates reported in Table $\mathrm{V}$ and Table VI show that the only field of study that was affected by the role model intervention, besides economics, is humanities. In particular, in Column 4 of Table VI we see that the role model visits significantly reduced the likelihood that female students majored in humanities. This suggests that the women nudged to study economics by the role model visits would have otherwise majored in humanities.

- Insert Table V here -

- Insert Table VI here -

\section{E. Performance of treated versus control female students in the economics study program}

An important follow up question is whether the performance of the treated female students, once they enter the economics study program, is in any way different than that of the untreated students. If the intervention had nudged into economics female students that were unlikely to do well in this field, this would be less than optimal for multiple reasons. First, the intervention would have possibly contributed to a misallocation of talents, where individuals pursuing a given major are not those who have a comparative advantage in it, as discussed in Hsieh et al. (2013). Second, if the female students who enrolled in Intermediate Economics classes as a result of the intervention were to perform less well then others, they would be less likely to enroll in upper level economics classes and ultimately major in economics. ${ }^{33}$ Hence, the role model intervention would have had only a short term impact on female students' choices and behaviors. Third, even if the students remained with the major, they may be worse off ex post, e.g., their graduation GPA would be lower than if they had majored in a different field and, as a result, their chances of getting a good job post graduation could suffer.

Comparing the performance of treated and control students in the economics classes they took after the Principles class is challenging, since, for instance, multiple sections of the same classes are usually offered by different professors, and teaching methods and grading systems vary widely across instructors. Here, we focus on performance in the Intermediate Microeconomics class, which is a prerequisite for most upper level economics classes. Besides reporting average grades obtained in Intermediate Micro, in Table VII we display the average scores obtained in a Core Exam, which all the students enrolled in Intermediate Microeconomics need to take toward the end of the semester. This exam provides a more objective measure of student performance, as it is prepared and administered by the economics department rather than the students' instructors, and it is the

\footnotetext{
${ }^{33}$ This is especially true given the empirical evidence on women's sensitivity to course grades (Goldin, 2013; Rask and Tiefenthaler, 2008).
} 
same for all the students enrolled in an Intermediate Microeconomics class in a given semester. ${ }^{34}$

- Insert Table VII here -

Descriptives on students' performance based on both the grade obtained in Intermediate Micro and the Core Exam, shown in Table VII, reveal that the treated female students performed as well, if not better, than the control female students. This suggests that the intervention did not nudge female students who were less likely to succeed in economics. Instead, it attracted seemingly qualified women who were previously not pursuing economics.

\section{Robustness checks}

\section{A. Pre-Intervention Trends}

An important assumption of the difference in differences estimation model is that, in the absence of the intervention under study, the difference between the treatment and control group would be constant over time. In order to check whether the assumption of parallel trends holds in our setting, we obtained data on our four outcome variables for the Spring 2014 cohort, i.e., the female students who took Principles classes in Spring 2014. Since the 2014 cohort enrolled in the Principles class before the start of our study, a total of 4 classes changed (in terms of instructor or teaching schedule) between Spring 2014 and Spring 2016. Therefore, our analysis is restricted to 7 classes -3 treatment classes and 4 control classes - that remained unchanged between the three years.

\section{- Insert Figure IV here -}

The top panel of Figure IV displays the pre-intervention trends for our intermediate outcomes: enrollment in Intermediate Micro the year after taking Principles, and enrollment in another economics class at any time after Principles. The bottom panel shows the pre-intervention trends for our final outcomes: the number of economics classes taken and the decision to major in economics. The pre-intervention trends are almost indistinguishable (and not statistically significantly different) for the female students in the 2014 and 2015 cohorts, whereas the post-treatment trends diverge sharply, with the women in the treatment classes in the 2016 cohort showing a significant increase in their enrollment rates, number of classes taken and majoring rate, whereas the women in the control classes follow the slight downward trend observed in previous years.

\footnotetext{
${ }^{34}$ In Fall 2015, there were 5 classes of ECO 3301 being offered, taught by 4 instructors. In Fall 2016, there were 4 classes being offered, taught by 3 professors. Of these 4 classes, 3 were the same as in Fall 2015. In Spring 2016 and Spring 2017, there were 4 classes offered, each taught by a different professor. Two classes were identical between the 2 years. Comparing the two academic years, in 2015-2016, 328 students were able to take Intermediate Micro, versus 304 in 2016-2017. Note that it is the department of Economics, not student demand, that decides the number of classes being offered every semester. The decision is made based on funding, instructor availability and classroom constraints.
} 


\section{B. Treatment effects on the grade obtained in Principles}

Since the intervention took place about a month before the end of the semester, it is possible that it affected student performance, for instance by inducing women to work harder. This could in turn be a channel through which the role model intervention may have impacted female students, as previous research (Goldin, 2013; Rask and Tiefenthaler, 2008) suggests that women's decision to pursue a given major may be conditional on obtaining a high grade in introductory courses.

In Section II.B, we noted that grades obtained in Principles were slightly but significantly lower for treated women in 2016. In Table VIII we report results from regression analysis on the grade achieved in the Principles class. We find that the grades observed in the treated classes are not lower because of the intervention; they are lower as a result of pre-intervention student characteristics, with students' cumulative GPA being the stronger predictor. Since the intervention did not improve grades in the class, we are able to rule out that channel of impact.

\section{- Insert Table VIII here -}

Note that, if the decision of female students to major in a given field is positively affected by the grades obtained in introductory classes, the lower average grades obtained by the treated women would work against us finding a positive impact of the role model intervention. In other words, the data show evidence of a positive impact of the intervention despite the fact that the treated female students tended to earn lower grades in the Principles class.

\section{Including class fixed-effects}

As noted earlier, nine Principles classes - 4 treatment classes and 5 control classes - remained unchanged between 2015 and 2016, i.e., were taught by the same instructor on the same day of the week and at the same time. In Table IX, we restrict the analysis to these 9 classes and include class fixed effects in the empirical specification.

\section{- Insert Table IX here -}

The top panel of Table IX shows estimates without controls, while the bottom panel results include individual controls, with the exception of class characteristics such as gender of the professor and class size. Even though the sample size is smaller, the main results are fairly robust. The estimated coefficients are similar in magnitude when class fixed effects are added. When controls are added, enrollment in Intermediate Micro the year following the intervention becomes marginally insignificant $(\mathrm{p}=0.11)$. Taking another economics class at any time after Principles remains significant $(\mathrm{p}=0.057)$. When looking at final outcomes, we see that the estimated coefficient of the number of economics classes taken 
loses significance. However, the impact on the choice to major in economics remains similar in magnitude to that observed in Table IV and significant at the 10 percent level.

\section{Effects on men}

We designed our intervention with the aim of impacting the population of female students enrolled in introductory economics classes. However, male students were also present during the role model visits. Here, we treat the men enrolled in principles classes as an additional control group and replicate the analysis on them as a 'placebo test' for the intervention.

\section{- Insert Figure V here -}

Figure V shows intermediate and final outcomes for the male students enrolled in control and treatment Principles classes in 2015 and 2016. We see no evidence of a significant effect of the intervention on any of our outcomes for the male sample. This is confirmed by regression analysis, displayed in Table A4 in Appendix.

In Table A5 in Appendix, we take the full sample of female and male students and include a triple interaction between a female student dummy, the year dummy, and the treatment class dummy. We also include controls and class fixed effects. ${ }^{35}$ The results confirm that the intervention had no impact on the male students, whereas it had a significant differential (positive) effect on the female students.

\section{Discussion on mechanisms}

Overall, the evidence presented in Sections II and III shows that a simple, and low cost role model intervention can significantly increase the percentage of women taking economics classes and ultimately majoring in economics. A possible limitation of our study is that we are unable to identify precisely which characteristics of the role models were the most important in influencing young women to pursue economics: whether it was that the careers they both had pursued were more attractive to women, yet not usually perceived as linked to the economics major, or simply personal experiences of success and their charisma which were inspiring and influential. This is because, by design, we aimed to choose the role models based on any combination of factors that would make them the most appealing to female undergraduate students. Hence, we decided to rely on the assessment of two current female economics majors, who perhaps implicitly knew best what would inspire their peers.

While disentangling experimentally the channels of role model influence is left to future research, we can gain some insights on the mechanisms at play in our intervention by examining our survey data. Specifically, in the self-administered

\footnotetext{
${ }^{35}$ Table A6 in Appendix reports results for the full sample with controls but without class fixed effects.
} 
questionnaire that we gave to the 2015 and the 2016 Principles of Economics spring cohorts, we asked students to list the jobs that they thought one could get with an economics degree. They could enter up to eight jobs. The caveat is that we have data only for the students who were in class the day of the survey and decided to answer the jobs question, i.e., a total of 429 female students $(68 \%$ of our sample).

The data shows that, as a result of the intervention, significantly more female students mentioned the fields of work of the two role models (marketing and management) as being associated with the economics major. ${ }^{36}$ In particular, 22 percent of the students in treated classes in 2016 mentioned either field as a potential sector of work versus only 6 percent in control classes $(p=0.001)$. In 2015, the percentages of students mentioning marketing or management were 9.65 percent in control classes and 10.62 percent in treatment classes and the difference is not statistically significant $(\mathrm{p}=0.749)$. This is clear evidence that the role models provided novel information to the students.

In order to assess whether the intervention worked through the observed increase in information on attainable jobs, we examine whether, as a result of the role model visits, we saw a decrease in the majors that are more directly related to the fields of work of the two role models, i.e., marketing and management. If this were the case, it would be evidence that the intervention worked by nudging into economics students who wanted a career in marketing or management and were previously planning to achieve it by majoring in those fields but that, because of the intervention, decided to do so with an economics degree. Figure II and Table $\mathrm{V}$ show that the intervention did not cause a decline in either the marketing major nor the business major, to which the field of management belongs. This indicates that the information given by the role models did not lead students who were planning to major in those fields to switch to economics.

Another possibility is that the new information on potential jobs associated with economics induced students who were not thinking of working in marketing or management to enter those fields, and to pursue an economics major to do so, just like the role models. Our survey data provide suggestive evidence that this is not the case. When examining the majors chosen by the female students who listed management or marketing among the jobs associated with economics, we see that none of these students ended up majoring in economics. This is true for both the control and the treatment classes.

Overall, the evidence suggests that, while the role models provided new information on the jobs that one could get with an economics degree, it is not such information that induced women to major in economics. We tentatively conclude that the intervention worked mainly through an inspiration rather than an information channel.

\footnotetext{
${ }^{36}$ We do not see a significant increase in the percentage of students who list the non-profit sector as a field of work.
} 


\section{Conclusions}

Closing the gender gap in quantitative, high-paying subjects such as economics is an important goal, which has proven remarkably stubborn to achieve. In this paper, we employed a field experiment to investigate the impact that female role models may play in young women's decisions to major in economics. The existing studies of role model effects in the context of majoring choices have been looking at the impact of female professors on female students' behaviors. Crucially, these studies raise questions about the identification of pure role model effects, since gender-specific teaching methods and/or behaviors toward same-gender students may confound the impact that female teachers may have on female students solely due to their ability to inspire them to model their choices after their own.

We employed role models who were not instructors and conducted a field experiment to clearly identify role model effects on women's choice of a male-dominated major. Specifically, we randomly selected Principles of Economics classes to receive short visits from two successful and charismatic career women who majored in economics at the same university. A crucial feature of our design is that we chose the role models with the help of two current female economics majors on the basis of their interest in the role models' careers and their assessment of the role models' communication skills and charisma. As a result, the fields of work of the chosen role models - non-profit, sale management and marketing - are not stereotypically associated with the economics major.

We found evidence of strong and large, given the baseline levels, effects of the role model visits on female students' enrolment in further economics classes and, ultimately, their decision to major in economics. In particular, the likelihood that a female student who took Principles of Economics would end up majoring in economics increased by about 8 percentage points (over a baseline level of 9 percent) as a result of the intervention.

Our majoring data also allowed us to examine which fields of study saw a decline in female students, allowing us to infer which majors the treated students would have chosen in the absence of the intervention. We found evidence that the women who were nudged to study economics would have otherwise majored in humanities. This suggests that our role model intervention could have a significant impact on the treated women's lifetime income streams, as the counterfactual seems to be that, absent the intervention, they would have ended up in lowerearning jobs. One concern could be that the intervention may have led to a misallocation of talents by attracting women who were unlikely to do well in the economics program. Our analysis of students' performance in Intermediate Microeconomics, as measured by a standardized test, shows that this is not the case, as the treated female students performed equally, if not better, than the female students in the control group. This indicates that the female students who were affected by the intervention were equally if not better equipped to succeed in the field; they were simply not considering economics as a possible major. 
Overall, the evidence presented shows that a simple, low cost and easily scalable intervention can significantly increase the percentage of women majoring in a male dominated field like economics. When examining possible mechanisms, we found no evidence that increased information about job choice was responsible for the observed impacts, leading us to conclude that the intervention may have worked through inspiration. Further work could compare male and female role models and their differential effects on male and female students, as well as experiment with the careers of the role models. The analysis could also be easily extended to other male-dominated or female-dominated fields of study. Overall, we consider this paper a first step in a rich potential area of research on role model effects, not only in undergraduate economics. 


\section{REFERENCES}

Abadie, Alberto, Susan Athey, Guido W Imbens, and Jeffrey Wooldridge. 2017. "When Should You Adjust Standard Errors for Clustering?" National Bureau of Economic Research 24003.

Allgood, Sam, William B Walstad, and John J Siegfried. 2015. "Research on teaching economics to undergraduates." Journal of Economic Literature, 53(2): $285-325$.

Angrist, Joshua D, and Jörn-Steffen Pischke. 2008. Mostly harmless econometrics: An empiricist's companion. Princeton University Press.

Arcidiacono, Peter. 2004. "Ability sorting and the returns to college major." Journal of Econometrics, 121(1): 343-375.

Athey, Susan, Christopher Avery, and Peter Zemsky. 2000. "Mentoring and Diversity." American Economic Review, 90(4): 765-786.

Bayer, Amanda, and Cecilia Elena Rouse. 2016. "Diversity in the Economics Profession: A New Attack on an Old Problem." The Journal of Economic Perspectives, 30(4): 221-242.

Beaman, Lori, Esther Duflo, Rohini Pande, and Petia Topalova. 2012. "Female leadership raises aspirations and educational attainment for girls: A policy experiment in India." science, 335(6068): 582-586.

Bear, Julia B, and Anita Williams Woolley. 2011. "The role of gender in team collaboration and performance." Interdisciplinary science reviews, 36(2): 146-153.

Bernard, Tanguy, Stefan Dercon, Kate Orkin, Alemayehu Taffesse, et al. 2014. The future in mind: Aspirations and forward-looking behaviour in rural Ethiopia. Centre for Economic Policy Research London.

Black, Dan A, Seth Sanders, and Lowell Taylor. 2003. "The economic reward for studying economics." Economic Inquiry, 41(3): 365-377.

Blau, Francine D, Janet M Currie, Rachel TA Croson, and Donna K Ginther. 2010. "Can Mentoring Help Female Assistant Professors? Interim Results from a Randomized Trial." The American Economic Review, 100(2): 348352.

Buser, Thomas, Muriel Niederle, and Hessel Oosterbeek. 2014. "Gender, competitiveness, and career choices." The Quarterly Journal of Economics, 129(3): 1409-1447.

Cameron, A Colin, and Douglas L Miller. 2015. "A practitioners guide to cluster-robust inference." Journal of Human Resources, 50(2): 317-372. 
Carnevale, Anthony P, and Ban Cheah. 2015. "From Hard Times to Better Times: College Majors, Unemployment, and Earnings." Georgetown University Center on Education and the Workforce.

Carrell, Scott E, Marianne E Page, and James E West. 2010. "Sex and science: How professor gender perpetuates the gender gap." The Quarterly Journal of Economics, 125(3): 1101-1144.

Chong, Alberto, and Eliana La Ferrara. 2009. "Television and divorce: Evidence from Brazilian novelas." Journal of the European Economic Association, $7(2-3):$ 458-468.

Dennehy, Tara C, and Nilanjana Dasgupta. 2017. "Female peer mentors early in college increase womens positive academic experiences and retention in engineering." Proceedings of the National Academy of Sciences, 114(23): 59645969 .

Dynan, Karen E, and Cecilia Elena Rouse. 1997. "The underrepresentation of women in economics: A study of undergraduate economics students." The Journal of Economic Education, 28(4): 350-368.

Ellison, Sara Fisher, and Wallace P Mullin. 2014. "Diversity, social goods provision, and performance in the firm." Journal of Economics $\&$ Management Strategy, 23(2): 465-481.

Emerson, Tisha LN, KimMarie McGoldrick, and Kevin J Mumford. 2012. "Women and the choice to study economics." The Journal of Economic Education, 43(4): 349-362.

Flory, Jeffrey A, Andreas Leibbrandt, and John A List. 2014. "Do competitive workplaces deter female workers? A large-scale natural field experiment on job entry decisions." The Review of Economic Studies, 82(1): 122-155.

Goldin, Claudia. 2013. "Notes on women and the undergraduate economics major." CSWEP Newsletter, 2013(15): 4-6.

Hoogendoorn, Sander, Hessel Oosterbeek, and Mirjam Van Praag. 2013. "The impact of gender diversity on the performance of business teams: Evidence from a field experiment." Management Science, 59(7): 1514-1528.

Hsieh, Chang-Tai, Erik Hurst, Charles I Jones, and Peter J Klenow. 2013. "The allocation of talent and us economic growth." National Bureau of Economic Research.

Jensen, Robert, and Emily Oster. 2009. "The power of TV: Cable television and women's status in India." The Quarterly Journal of Economics, 124(3): 1057-1094. 
Kirkeboen, Lars J, Edwin Leuven, and Magne Mogstad. 2016. "Field of study, earnings, and self-selection." The Quarterly Journal of Economics, 131(3): 1057-1111.

Kline, Patrick, Andres Santos, et al. 2012. "A score based approach to wild bootstrap inference." Journal of Econometric Methods, 1(1): 23-41.

Kofoed, Michael S, et al. 2019. "The Effect of Same-Gender or Same-Race Role Models on Occupation Choice Evidence from Randomly Assigned Mentors at West Point." Journal of Human Resources, 54(2): 430-467.

Kugler, Adriana D, Catherine H Tinsley, and Olga Ukhaneva. 2017. "Choice of Majors: Are Women Really Different from Men?" National Bureau of Economic Research 23735.

La Ferrara, Eliana, Alberto Chong, and Suzanne Duryea. 2012. "Soap operas and fertility: Evidence from Brazil." American Economic Journal: Applied Economics, 4(4): 1-31.

Lim, Jaegeum, and Jonathan Meer. 2019. "Persistent effects of teacherstudent gender matches." Journal of Human Resources, 0218-9314R4.

Lockwood, Penelope. 2006. "Someone Like Me Can Be Successful: Do College Students Need Same-Gender Role Models?" Psychology of Women Quarterly, 30(1): 36-46.

May, Ann Mari, Mary G McGarvey, and David Kucera. 2018. "Gender and European Economic Policy: A Survey of the Views of European Economists on Contemporary Economic Policy." Kyklos, 71(1): 162-183.

May, Ann, Mary G McGarvey, and Robert Whaples. 2014. "Are disagreements among male and female economists marginal at best?: A survey of AEA members and their views on economics and economic policy." Contemporary Economic Policy, 32(1): 111-132.

Morgenroth, Thekla, Michelle K Ryan, and Kim Peters. 2015. "The motivational theory of role modeling: How role models influence role aspirants goals." Review of General Psychology, 19(4): 465-483.

Nguyen, Trang. 2008. "Information, role models and perceived returns to education: Experimental evidence from Madagascar."

Niederle, Muriel, and Lise Vesterlund. 2007. "Do women shy away from competition? Do men compete too much?" The Quarterly Journal of Economics, 122(3): 1067-1101.

Rask, Kevin, and Jill Tiefenthaler. 2008. "The role of grade sensitivity in explaining the gender imbalance in undergraduate economics." Economics of Education Review, 27(6): 676-687. 
Reuben, Ernesto, Matthew Wiswall, and Basit Zafar. 2017. "Preferences and biases in educational choices and labour market expectations: Shrinking the black box of gender." The Economic Journal, 127(604): 2153-2186.

Riley, Emma. 2017. "Role models in movies: the impact of Queen of Katwe on students educational attainment." Centre for the Study of African Economies, University of Oxford.

Roodman, David, Morten Ørregaard Nielsen, James G MacKinnon, and Matthew D Webb. 2019. "Fast and wild: Bootstrap inference in Stata using boottest." The Stata Journal, 19(1): 4-60.

Stevenson, Betsey, and Hanna Zlotnik. 2018. "Representations of men and women in introductory economics textbooks." Vol. 108, 180-85.

Stout, Jane G, Nilanjana Dasgupta, Matthew Hunsinger, and Melissa A McManus. 2011. "STEMing the tide: using ingroup experts to inoculate women's self-concept in science, technology, engineering, and mathematics (STEM)." Journal of personality and social psychology, 100(2): 255.

Wiswall, Matthew, and Basit Zafar. 2014. "Determinants of college major choice: Identification using an information experiment." The Review of Economic Studies, 82(2): 791-824.

Wiswall, Matthew, and Basit Zafar. 2017. "Preference for the workplace, investment in human capital, and gender." The Quarterly Journal of Economics, 133(1): 457-507. 
Tables and Figures

Table I-Balance Tests

\begin{tabular}{|c|c|c|c|c|c|c|}
\hline & $\begin{array}{c}\text { Control } \\
\text { classes } \\
2015 \\
\text { (untreated) }\end{array}$ & $\begin{array}{c}\text { Treatment } \\
\text { classes } \\
2015 \\
\text { (untreated) }\end{array}$ & $\begin{array}{c}\text { p-value } \\
\text { diff }\end{array}$ & $\begin{array}{c}\text { Control } \\
\text { classes } \\
2016 \\
\text { (untreated) }\end{array}$ & $\begin{array}{c}\text { Treatment } \\
\text { classes } \\
2016 \\
\text { (treated) }\end{array}$ & $\begin{array}{c}\text { p-value } \\
\text { diff }\end{array}$ \\
\hline American student & 92.95 & 94.51 & $(0.56)$ & 92.09 & 79.23 & $(0.00)$ \\
\hline In-state student & 22.44 & 24.39 & $(0.68)$ & 20.34 & 21.54 & $(0.80)$ \\
\hline Freshman & 83.97 & 85.37 & $(0.73)$ & 83.05 & 95.38 & $(0.00)$ \\
\hline Cumulative GPA & 3.44 & 3.41 & $(0.52)$ & 3.48 & 3.39 & $(0.06)$ \\
\hline Belongs to sorority ${ }^{+}$ & 65.08 & 65.00 & $(0.99)$ & 67.46 & 58.72 & $(0.17)$ \\
\hline Took econ in high school ${ }^{+}$ & 53.97 & 61.87 & $(0.19)$ & 59.06 & 55.96 & $(0.63)$ \\
\hline Athlete $^{+}$ & 7.14 & 5.71 & $(0.63)$ & 6.40 & 10.09 & $(0.30)$ \\
\hline
\end{tabular}

Notes: Percentages, except GPA. Test is of equality between treatment and control groups in the corresponding year. Sample size 627 women. + indicates survey variable (survey responses sample size 502 women). 
TABle II-OUtcome VARIABLES BY TREATMENT ClASS AND YeAR

\begin{tabular}{|c|c|c|c|c|c|c|}
\hline & $\begin{array}{c}\text { Control } \\
\text { classes } \\
2015 \\
\text { (untreated) }\end{array}$ & $\begin{array}{c}\text { Treatment } \\
\text { classes } \\
2015 \\
\text { (untreated) }\end{array}$ & $\begin{array}{c}\text { p-value } \\
\text { diff }\end{array}$ & $\begin{array}{c}\text { Control } \\
\text { classes } \\
2016 \\
\text { (untreated) }\end{array}$ & $\begin{array}{c}\text { Treatment } \\
\text { classes } \\
2016 \\
\text { (treated) }\end{array}$ & $\begin{array}{c}\text { p-value } \\
\text { diff }\end{array}$ \\
\hline \multicolumn{7}{|l|}{ Female } \\
\hline Took Interm. Micro within year & 14.74 & 10.98 & $(0.31)$ & 10.73 & 18.46 & $(0.05)$ \\
\hline Took another Econ class & 23.72 & 18.90 & $(0.29)$ & 17.51 & 28.46 & $(0.02)$ \\
\hline Num of further Econ classes taken & 1.03 & 0.90 & $(0.66)$ & 0.85 & 1.42 & $(0.08)$ \\
\hline Majored in Economics & 10.26 & 7.93 & $(0.46)$ & 7.91 & 15.38 & $(0.04)$ \\
\hline
\end{tabular}

Notes: Percentages, except number of economics classes taken. Test is of equality between treatment and control groups in the corresponding year. $N=627$. 
Table III-Treatment Effects on Intermediate Outcomes

\begin{tabular}{lcc|cc}
\hline & $\begin{array}{c}\text { Took Micro } \\
\text { within year }\end{array}$ & $\begin{array}{c}\text { Took Micro } \\
\text { within year }\end{array}$ & $\begin{array}{c}\text { Took Another } \\
\text { Econ class }\end{array}$ & $\begin{array}{c}\text { Took Another } \\
\text { Econ class }\end{array}$ \\
\hline Treatment class x 2016 & 0.115 & 0.112 & 0.158 & 0.139 \\
& $(0.004)$ & $(0.009)$ & $(0.030)$ & $(0.032)$ \\
& {$[0.034,0.208]$} & {$[0.022,0.214]$} & {$[0.013,0.257]$} & {$[0.012,0.268]$} \\
& -0.040 & -0.049 & -0.062 & -0.067 \\
& $(0.182)$ & $(0.239)$ & $(0.002)$ & $(0.084)$ \\
Year 2016 & {$[-0.144,0.027]$} & {$[-0.146,0.031]$} & {$[-0.123,-0.037]$} & {$[-0.144,0.009]$} \\
& -0.038 & -0.047 & -0.048 & -0.061 \\
Constant & $(0.175)$ & $(0.017)$ & $(0.072)$ & $(0.036)$ \\
& {$[-0.105,0.021]$} & {$[-0.094,-0.015]$} & {$[-0.091,0.004]$} & {$[-0.094,-0.009]$} \\
Controls & 0.147 & 0.372 & 0.237 & 0.803 \\
Observations & $(0.000)$ & $(0.010)$ & $(0.004)$ & $(0.001)$ \\
& {$[0.115,0.207]$} & {$[0.160,0.622]$} & {$[0.167,0.272]$} & {$[0.322,1.286]$} \\
\hline
\end{tabular}

Notes: LPM regressions. We report wild bootstrap cluster p-values in parentheses and wild bootstrap cluster $95 \%$ confidence intervals in square brackets, generated using boottest command in Stata 14 (Roodman et al., 2019) for standard errors clustered at the class level (12 clusters). In columns 1 and 2 the dependent variable is a dummy equal 1 if student took Intermediate Micro the year after the Principles class. In columns 3 and 4 the dependent variable is a dummy equal to 1 if the student enrolled in another economics class at any time after the Principles class (up to January 2019). 
Table IV-Treatment effects on Final Outcomes

\begin{tabular}{lcc|cc}
\hline & $\begin{array}{c}\text { Num Econ } \\
\text { classes taken }\end{array}$ & $\begin{array}{c}\text { Num Econ } \\
\text { classes taken }\end{array}$ & $\begin{array}{c}\text { Major in } \\
\text { Economics }\end{array}$ & $\begin{array}{c}\text { Major in } \\
\text { Economics }\end{array}$ \\
\hline Treatment class x 2016 & 0.692 & 0.522 & 0.098 & 0.080 \\
& $(0.039)$ & $(0.115)$ & $(0.018)$ & $(0.089)$ \\
Year 2016 & {$[0.052,1.18]$} & {$[-0.157,1.094]$} & {$[0.019,0.161]$} & {$[-0.015,0.160]$} \\
& -0.173 & -0.189 & -0.023 & -0.028 \\
Treatment class (in 2015) & $(0.288)$ & $(0.479)$ & $(0.357)$ & $(0.469)$ \\
& $-0.524,0.188]$ & {$[-0.749,0.334]$} & {$[-0.073,0.047]$} & {$[-0.118,0.0863]$} \\
& -0.129 & -0.206 & -0.023 & -0.030 \\
Constant & $(0.507)$ & $(0.442)$ & $(0.431)$ & $(0.365)$ \\
& $1-0.665,0.265]$ & {$[-0.715,0.415]$} & {$[-0.099,0.035]$} & {$[-0.092,0.054]$} \\
Controls & 1.026 & 5.804 & 0.103 & 0.510 \\
Observations & $(0.002)$ & $(0.001)$ & $(0.004)$ & $(0.008)$ \\
\hline \hline
\end{tabular}

Notes: Column (1-2) OLS regressions, column (3-4) LPM regressions. We report wild bootstrap cluster p-values in parentheses and wild bootstrap cluster $95 \%$ confidence intervals in square brackets, generated using boottest command in Stata 14 (Roodman et al., 2019) for standard errors clustered at the class level (12 clusters). In columns 1 and 2 the dependent variable is the number of economics classes taken after the Principles class. In columns 3 and 4 the dependent variable is a dummy equal to 1 if student majored in economics (or declared the economics major, if student has not graduated yet). 
Table V-Treatment effects on Other High-earning Majors

\begin{tabular}{lcccc}
\hline & Major & Major & Major & Major \\
& STEM & Finance & Business & Marketing \\
\hline Treatment class x 2016 & 0.013 & 0.026 & 0.078 & -0.018 \\
& $(0.872$ & $(0.733)$ & $(0.212)$ & $(0.846)$ \\
& {$[-0.192,0.187]$} & {$[-0.166,0.170]$} & {$[-0.095,0.199]$} & {$[-0.190,0.149]$} \\
& 0.003 & -0.005 & -0.057 & 0.029 \\
& $(0.960)$ & $(0.929)$ & $(0.064)$ & $(0.460)$ \\
Trear 2016 & {$[-0.070,0.190]$} & {$[-0.153,0.137]$} & {$[-0.208,0.005]$} & {$[-0.065,0.125]$} \\
& -0.005 & -0.030 & -0.037 & 0.037 \\
Constant & $(0.900)$ & $(0.409)$ & $(0.481)$ & $(0.451)$ \\
& {$[-0.118,0.153]$} & {$[-0.121,0.051]$} & {$[-0.172,0.097]$} & {$[-0.052,0.129]$} \\
& 0.245 & -0.154 & -0.319 & -0.255 \\
Controls & $(0.171)$ & $(0.504)$ & $(0.067)$ & $(0.021)$ \\
\hline Observations & {$[-0.103,0.577]$} & {$[-0.659,0.408]$} & {$[-0.729,0.016]$} & {$[-0.471,-0.035]$} \\
\hline
\end{tabular}

Notes: LPM regressions. We report wild bootstrap cluster p-values in parentheses and wild bootstrap cluster $95 \%$ confidence intervals in square brackets, generated using boottest command in Stata 14 (Roodman et al., 2019) for standard errors clustered at the class level (12 clusters). Dependent variables: Dummy equal to 1 if student majored in (1) STEM subjects (2) Finance (3) Business (4) Marketing. 
Table VI-Treatment Effects on Low-Earning Majors

\begin{tabular}{lcccc}
\hline & Major & Major & Major & Major \\
& Soc.Sciences & Arts & Communication & Humanities \\
\hline Treatment class x 2016 & -0.006 & -0.031 & -0.012 & -0.141 \\
& $(0.918)$ & $(0.448)$ & $(0.664)$ & $(0.002)$ \\
& {$[-0.109,0.139]$} & {$[-0.109,0.082]$} & {$[-0.076,0.039]$} & {$[-0.200,-0.073]$} \\
& -0.023 & 0.018 & -0.008 & 0.067 \\
& $(0.569)$ & $(0.152)$ & $(0.774)$ & $(0.015)$ \\
Year 2016 & {$[-0.178,0.066]$} & {$[-0.013,0.045]$} & {$[-0.051,0.071]$} & {$[0.028,0.131]$} \\
& -0.037 & 0.035 & -0.002 & 0.083 \\
Treatment class (in 2015) & $(0.371)$ & $(0.137)$ & $(0.921)$ & $(0.039)$ \\
& {$[-0.137,0.043]$} & {$[-.013,0.096]$} & {$[-0.036,0.056]$} & {$[0.006,0.161]$} \\
& 0.624 & 0.050 & 0.146 & 0.140 \\
Constant & $(0.002)$ & $(0.501)$ & $(0.075)$ & $(0.363)$ \\
& {$[0.317,1.162]$} & {$[-0.100,0.249]$} & {$[-0.027,0.331]$} & {$[-0.148,0.386]$} \\
Controls & Yes & Yes & Yes & Yes \\
\hline Observations & 627 & 627 & 627 & 627 \\
\hline
\end{tabular}

Notes: LPM regressions. We report wild bootstrap cluster p-values in parentheses and wild bootstrap cluster $95 \%$ confidence intervals in square brackets, generated using boottest command in Stata 14 (Roodman et al., 2019) for standard errors clustered at the class level (12 clusters). Dependent variables: Dummy equal to 1 if student majored in (1) Social Science (other than economics), (2) Arts, (3) Communication studies, (4) Humanities. 
Table ViI-Performance in Intermediate Microeconomics by treatment Class and year

\begin{tabular}{|c|c|c|c|c|c|c|}
\hline & $\begin{array}{c}\text { Control } \\
\text { classes } \\
2015 \\
\text { (untreated) }\end{array}$ & $\begin{array}{c}\text { Treatment } \\
\text { classes } \\
2015 \\
\text { (untreated) }\end{array}$ & p-value & $\begin{array}{c}\text { Control } \\
\text { classes } \\
2016 \\
\text { (untreated) }\end{array}$ & $\begin{array}{c}\text { Treatment } \\
\text { classes } \\
2016 \\
\text { (treated) }\end{array}$ & $\mathrm{p}$-value \\
\hline Average grade & 3.32 & 3.36 & $(0.84)$ & 3.02 & 3.24 & $(0.49)$ \\
\hline Core Exam score & 0.62 & 0.60 & $(0.74)$ & 0.59 & 0.69 & $(0.24)$ \\
\hline
\end{tabular}

Notes: Test is of equality of means between treatment and control groups in the corresponding year. 
Table Vili-Robustness: Treatment Effects on Grade in Principles class

\begin{tabular}{lcccc}
\hline & Grade & Grade & Grade & Grade \\
& Principles & Principles & Principles & Principles \\
\hline Treatment class x 2016 & -0.244 & -0.142 & -0.093 & -0.075 \\
& $(0.363)$ & $(0.392)$ & $(0.686)$ & $(0.685)$ \\
Year 2016 & {$[-0.757,0.341]$} & {$[-0.455,0.238]$} & {$[-0.587,0.489]$} & {$[-0.427,0.303]$} \\
& 0.090 & 0.046 & -0.066 & -0.026 \\
Treatment class (in 2015) & $(0.745)$ & $(0.748)$ & $(0.845)$ & $(0.910)$ \\
& $-0.423,0.478]$ & {$[-0.326,0.344]$} & {$[-0.543,0.444]$} & {$[-0.379,0.650]$} \\
Constant & -0.009 & 0.067 & & \\
& $(0.975)$ & $(0.561)$ & & \\
Controls & $-0.455,0.458]$ & {$[-0.209,0.237]$} & & \\
Class Fixed Effects & 3.019 & -1.890 & 2.682 & -1.858 \\
\hline Observations & $(0.002)$ & $(0.016)$ & $(0.005)$ & $(0.022)$ \\
\hline
\end{tabular}

Notes: OLS regressions. We report wild bootstrap cluster p-values in parentheses and wild bootstrap cluster $95 \%$ confidence intervals in square brackets, generated using boottest command in Stata 14 (Roodman et al., 2019) for standard errors clustered at the class level (12 clusters). Dep. Variable: Grade obtained in Principles of Economics class. 
Table IX-Robustness: Including Class Fixed Effects

\begin{tabular}{lcccc}
\hline No controls & $\begin{array}{c}\text { Took } \\
\text { Micro }\end{array}$ & $\begin{array}{c}\text { Took } \\
\text { Another }\end{array}$ & $\begin{array}{c}\text { Number } \\
\text { Econ classes }\end{array}$ & $\begin{array}{c}\text { Major } \\
\text { Economics }\end{array}$ \\
\hline Treatment class x 2016 & 0.097 & 0.142 & 0.540 & 0.096 \\
& $(0.047)$ & $(0.039)$ & $(0.078)$ & $(0.040)$ \\
& {$[0.001,0.206]$} & {$[0.008,0.265]$} & {$[-0.090,1.074]$} & {$[0.004,0.171]$} \\
& -0.011 & -0.036 & 0.036 & -0.011 \\
& $(0.710)$ & $(0.163)$ & $(0.811)$ & $(0.694)$ \\
Year 2016 & {$[-0.205,0.059]$} & {$[-0.206,0.049]$} & {$[-0.826,0.345]$} & {$[-0.100,0.107]$} \\
& 0.066 & 0.199 & 1.000 & 0.067 \\
& $(0.524)$ & $(0.211)$ & $(0.140)$ & $(0.446)$ \\
Observations & {$[-0.160,0.817]$} & {$[-0.379,1.105]$} & {$[-1.095,3.936]$} & {$[-0.061,0.508]$} \\
\hline Including controls & 570 & 570 & 570 & 570 \\
\hline Treatment class x 2016 & 0.091 & & & \\
& $(0.101)$ & $(0.057)$ & $(0.169)$ & $(0.097)$ \\
Year 2016 & {$[-0.015,0.201]$} & {$[-0.003,0.253]$} & {$[-0.188,1.014]$} & {$[-0.018,0.164]$} \\
& -0.017 & -0.050 & -0.061 & -0.023 \\
Constant & $(0.550)$ & $(0.083)$ & $(0.785)$ & $(0.518)$ \\
& {$[-0.203,0.044]$} & {$[-0.221,0.013]$} & {$[-1.225,0.302]$} & {$[-0.151,0.128]$} \\
& 0.312 & 0.799 & 5.840 & 0.487 \\
& $(0.063)$ & $(0.012)$ & $(0.005)$ & $(0.075)$ \\
\hline Observations & {$[-0.027,0.626]$} & {$[0.273,1.360]$} & {$[1.466,9.312]$} & {$[-0.036,1.019]$} \\
\hline
\end{tabular}

Notes: LPM/OLS regressions with class fixed effects. We report wild bootstrap cluster p-values in parentheses and wild bootstrap cluster $95 \%$ confidence intervals in square brackets, generated using boottest command in Stata 14 (Roodman et al., 2019) for standard errors clustered at the class level (9 clusters). Dependent variables: (1) Dummy equal to 1 if student took Intermediate Micro the year after Principles, (2) dummy equal to 1 if she enrolled in another economics class since Principles (up to January 2019); (3) Number of economics classes taken (OLS regression); (4) Dummy equal to 1 if she majored in economics. 
Figure I. OUtComes Before AND AFter treAtment

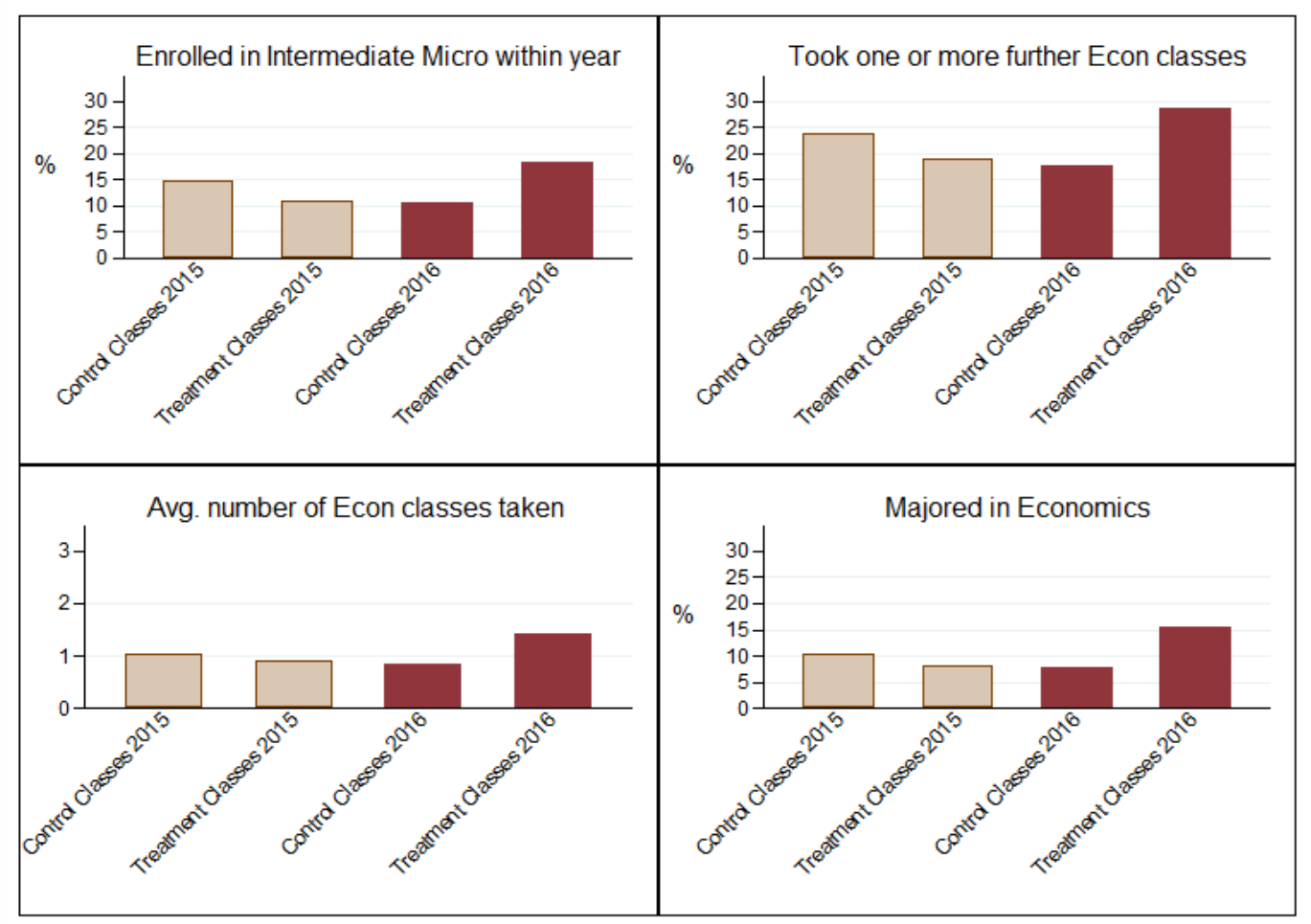


Figure II. MAJor IN OTHER HIGH-EARNing FIELDS BEFore AND AFter trEATMENT

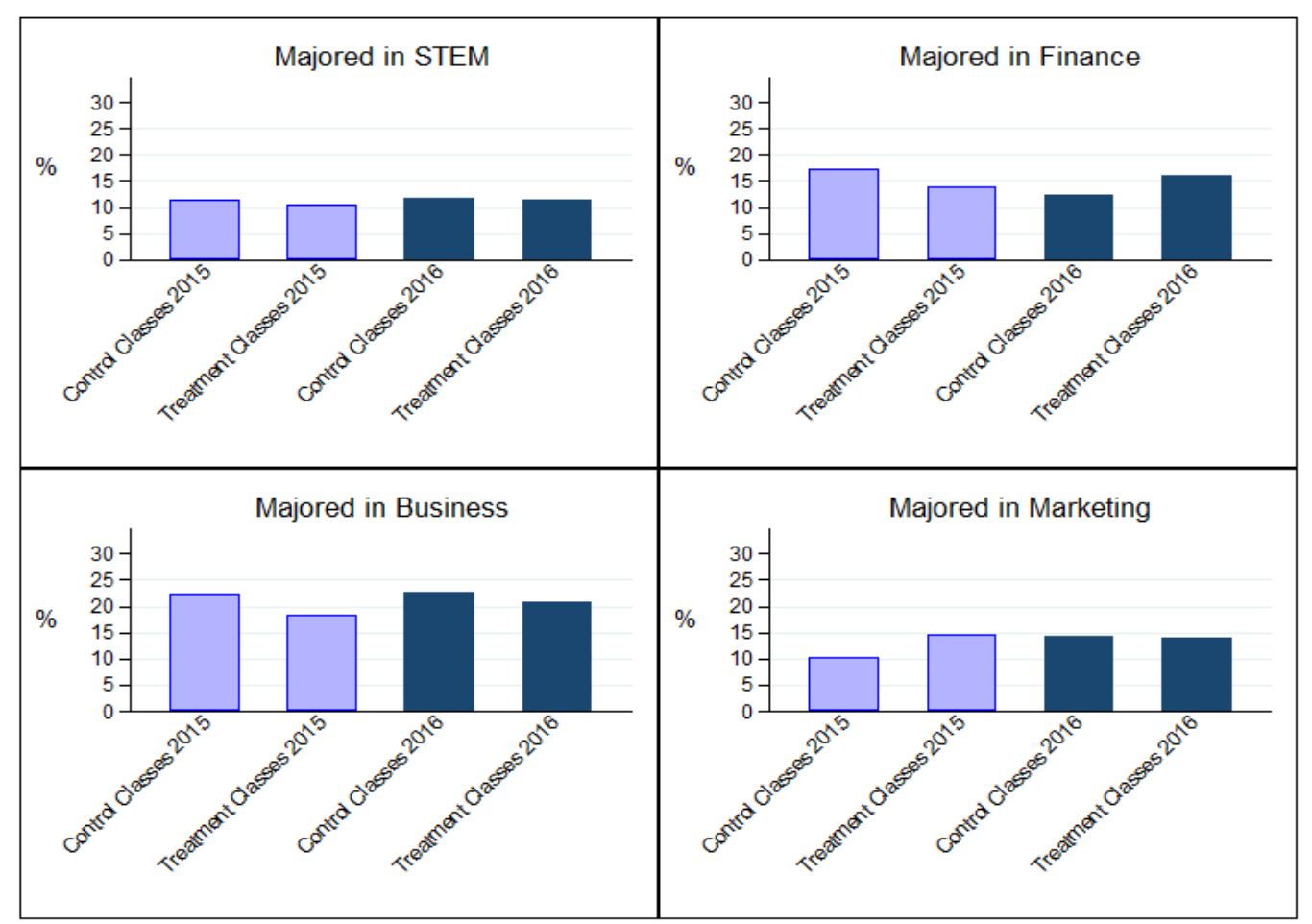


Figure III. MAJOR IN LOWER-EARNING FIELDS BEFore AND AFTER TREATMENT

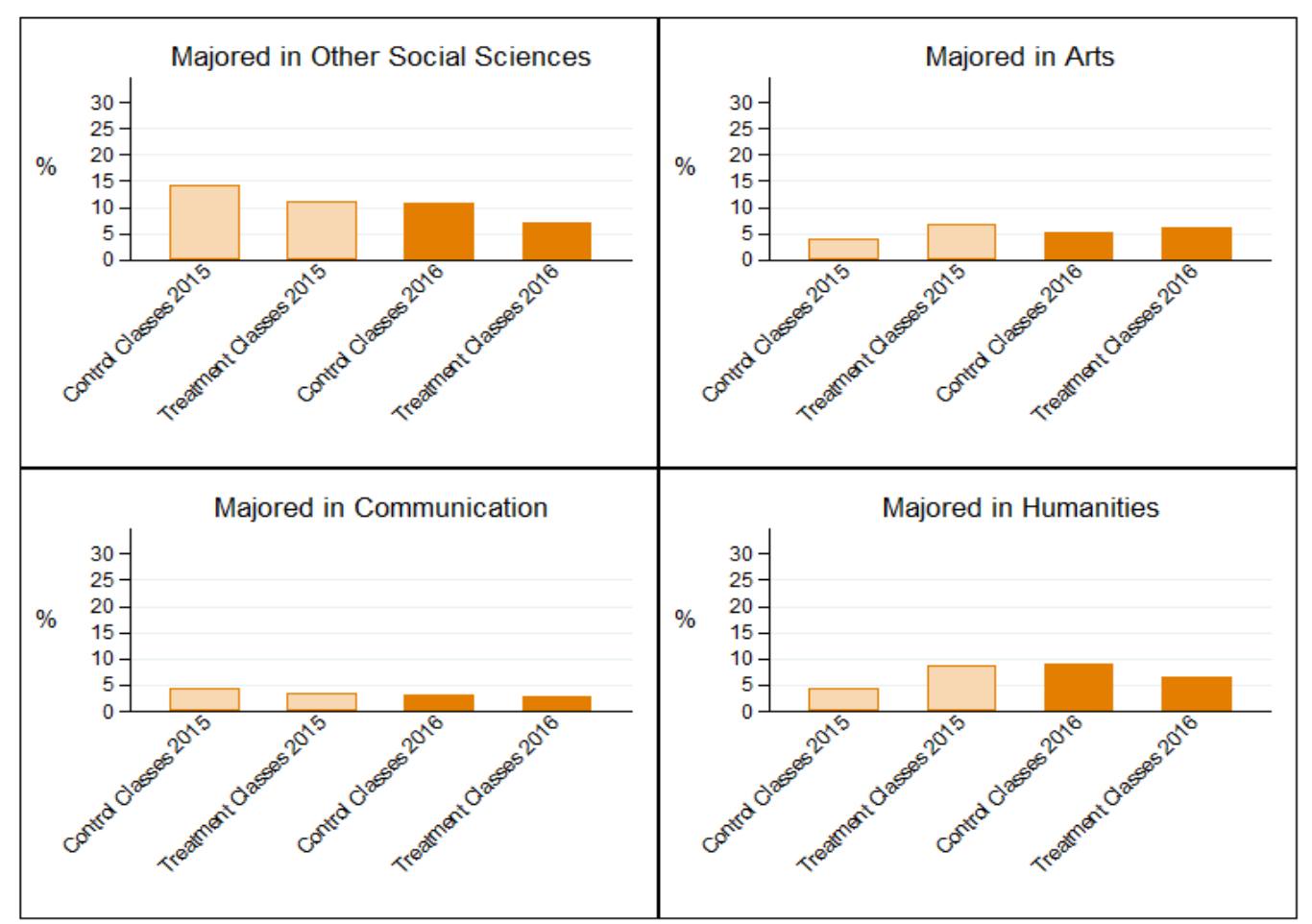


Figure IV. Common trends

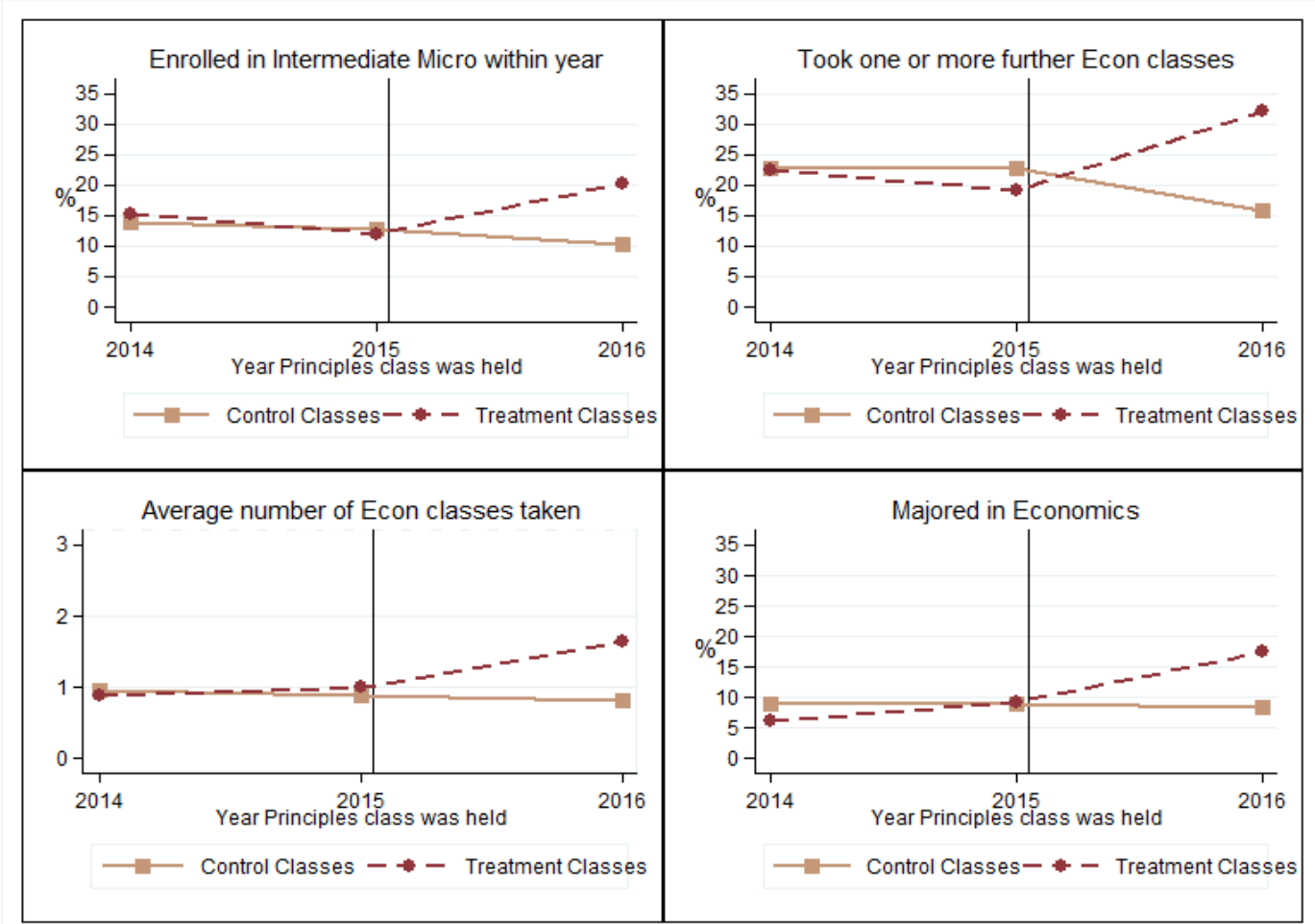


Figure V. Male Students: Outcomes Before and After treatment

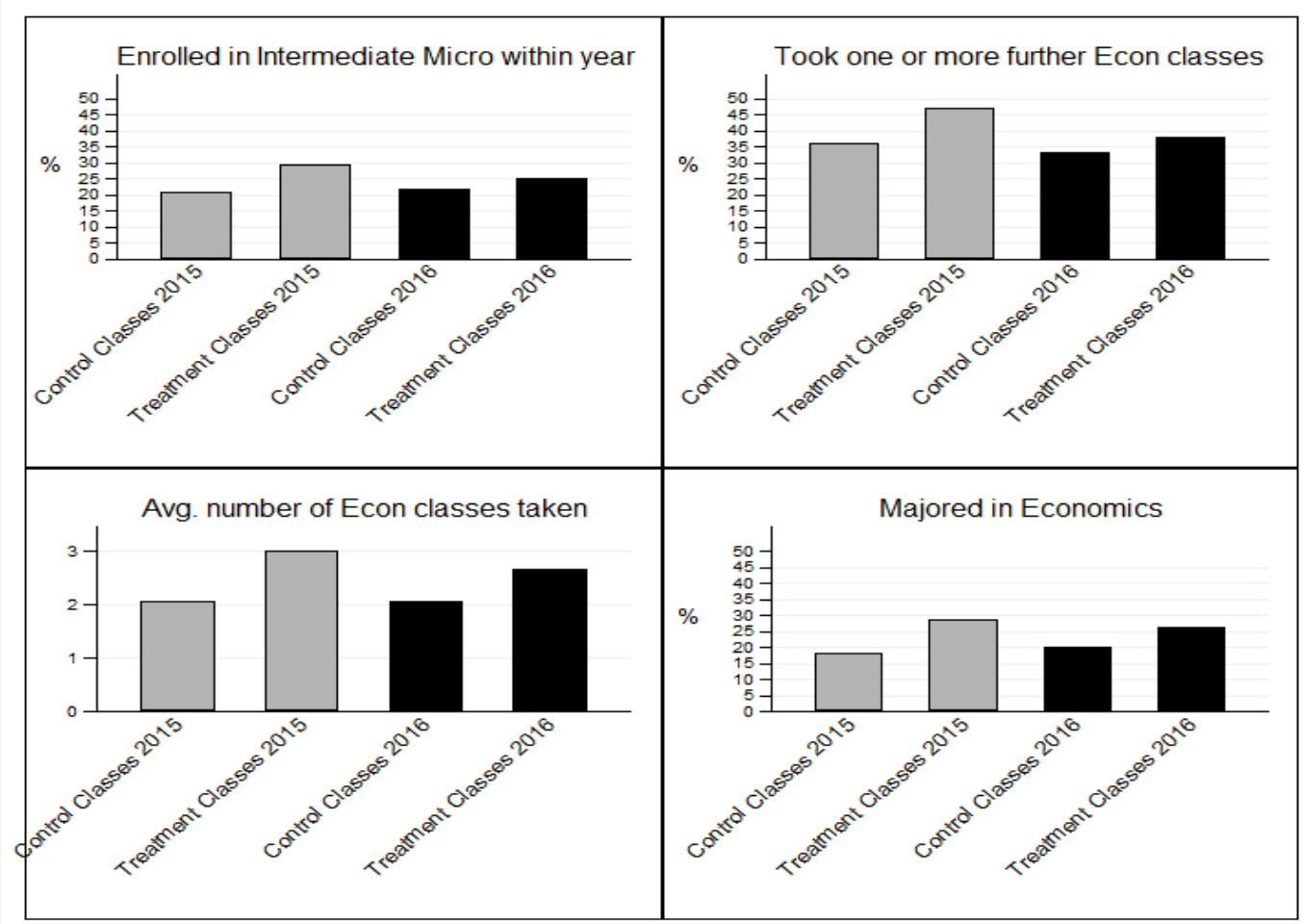

